\title{
O DIREITO DO PODER ADMINISTRATIVO: ENTRE JURIDIFICAÇÃO INSTRUMENTAL E COMUNICAÇÃO RACIONAL - UMA LEITURA DO CAPÍTULO IV DE "FACTICIDADE E VALIDADE", DE JÜRGEN HABERMAS
}

THE ADMINISTRATIVE POWER LAW: BETWEEN INSTRUMENTAL JURIDIFICATION AND

RATIONAL COMMUNICATION - A READING OF CHAPTER IV OF JÜRGEN HABERMAS' BETWEEN

FACTS AND NORMS

\section{Marco Antônio Moraes Alberto*}

\begin{abstract}
Resumo:
Este artigo tem o objetivo de propor uma leitura do capítulo IV de Direito e democracia: entre facticidade e validade, de Jürgen Habermas, que seja capaz de, simultaneamente, abarcar as diferenças de diagnóstico do autor sobre o direito público e evidenciar nesse diagnóstico uma linha de continuidade crítica. Entendendo o conceito de "reconstrução" como eixo da teoria social habermasiana, este artigo examina dois momentos da reconstrução do direito público na visão do autor. No primeiro, analisa-se como a teoria da ação comunicativa, ao pressupor a oposição entre poder administrativo e ação comunicativa, afirma a instrumentalidade do direito público à pretensão colonizadora dos sistemas político e jurídico sobre o mundo da vida (diagnóstico da juridificação). No segundo, enfatiza-se a constitucionalidade do direito sobre a esfera pública, o que abre espaço para o diagnóstico do potencial do mundo da vida em criar espaços de comunicação racional em oposição à pretensão instrumental e reificante do sistema jurídico e do poder administrativo (diagnóstico da constitucionalização). Em sua conclusão, o artigo argumenta que a continuidade entre os dois momentos deve ser encontrada na pretensão de legitimidade do direito ocupado em regular o poder administrativo.
\end{abstract}

Palavras-chave: Habermas. Direito público. Legitimidade.

\begin{abstract}
:
The purpose of this paper is to provide a reading of Chapter IV of Jürgen Habermas' Between facts and norms. This reading must be able to, simultaneously, frame Public Law approach differences developed by the author, and display, inside these approaches, a critical guideline. Departing from the centrality of the concept of "reconstruction" in Habermas' social theory, this article investigates two different
\end{abstract}

\footnotetext{
* Doutorando em Direito do Estado pela Universidade de São Paulo. Bacharel em Direito pela Universidade de São Paulo (FDUSP). Pesquisador do Departamento de Direito do Estado da Universidade de São Paulo (DES-USP). Pesquisador bolsista da Fundação de Amparo à Pesquisa do Estado de São Paulo (FAPESP). Assistente de docência e de produção no Departamento de Direito do Estado da Faculdade de Direito da Universidade de São Paulo (FDUSP). Assessor de pesquisa jurídica na Controladoria Geral da Universidade de São Paulo (CG-USP). Professor, consultor e advogado parecerista em São Paulo. O autor gostaria de agradecer a Alexandre Braga Massella, Bianca Tavolari, Celso Fernandes Campilongo, Cicero Romão Resende de Araujo, Conrado Hübner Mendes, Daniel Peixoto Murata, Fernando Dias Menezes de Almeida, Henrique Almeida de Castro, Rúrion Soares Melo e Vitor Rhein Schirato pela leitura e pelos comentários a versões preliminares deste artigo, bem como pelo incentivo à sua publicação.
} 
moments on Public Law's reconstruction inside Habermas' view. Firstly, the article analyzes how the theory of communicative action, by opposing administrative power and communicative action, endorses the instrumentality of Public Law in order to insure lifeworld colonization by legal and administrative systems (juridification diagnosis). Secondly, this article analyzes Habermas' emphasis on Public Law constitutionality over public sphere, which makes feasible the verification of a lifeworld potential to create rational communicative spaces in opposition to reifying and instrumental pretensions by legal system and administrative power (constitutionalization diagnosis). This article concludes sustaining that the critical guideline which integrates these two different moments must be found in the legitimacy claim of the Law committed to administrative power regulation.

Keywords: Habermas. Public Law. Legitimacy.

\section{Introdução}

Jürgen Habermas é um autor de fôlego. Tendo escrito uma extensa bibliografia em teoria social, inovou decisivamente a chamada "teoria crítica", como principal expoente de sua dita "segunda geração". Seja pela proposta de uma nova abordagem metodológica no campo da teoria crítica, trazendo para seu interior o denominado "paradigma da comunicação", ${ }_{1}^{1}$ seja pela atenção que sua formulação dispensa a fenômenos até então tratados apenas marginalmente pelas ciências sociais, caso dos movimentos civis, da participação democrática e da constitucionalização do direito, fato é que a obra de Habermas, além de muito vasta, é extraordinariamente diversificada.

Dentro desse amplo universo, o objeto específico do presente artigo é apontar a silhueta assumida pela parcela do direito que se ocupa estritamente do poder administrativo ("direito público"), tomando-se como índice o que Habermas define no capítulo IV da obra "Facticidade e validade" (1992). ${ }^{2}$ A atenção, aqui, estará voltada não apenas aos elementos constitutivos dessa definição, mas também ao caráter inovador dessa proposta teórica em relação ao que havia sido o diagnóstico anteriormente sugerido pelo autor acerca da relação entre sistema jurídico e poder administrativo, tal como desenvolvido especialmente no período entre a publicação de "Mudança estrutural da esfera pública:

\footnotetext{
1 Para esse ponto, vide o segundo capítulo da apresentação de Finlayson (2012, p. 16-27). Vide também, especificamente para a importância e o significado da incorporação do paradigma da comunicação pela teoria crítica pela via da teoria social de Habermas, a introdução à teoria crítica escrita por Axel Honneth (1999, p. 503-552). Vide ainda, para uma análise do enraizamento deste paradigma na compreensão hegeliana de que a autoconsciência, enquanto distanciamento da experiência humana de sua imediatidade sensorial, haveria de ser entendida em termos da comunicação entre os seres humanos por meio das categorias de significado compreendidas na linguagem, Giddens (2011, p. 297-312).

2 Apesar de a tradução anglófona (1996), sobre a qual trabalho neste artigo, sugerir "between facts and norms", uso aqui "facticidade e validade", por considerar a tradução mais adequada para o título da obra no original alemão, "Faktizität und Geltung".
} 
investigações sobre uma categoria da sociedade burguesa" (1962) e dos dois volumes da "Teoria do agir comunicativo" (1981). O objetivo é, portanto, o de brevemente apontar e discutir o modo segundo o qual duas reconstruções teóricas diferentes, no interior da obra de Habermas, desembocam em duas perspectivas igualmente possíveis a respeito do papel do direito público na produção da práxis social. ${ }^{3}$

\section{Quatro ressalvas metodológicas}

Essa constatação é relevante para a delimitação do objeto deste artigo. Não me proponho a fazer, aqui, uma análise da "obra" de Habermas, nem muito menos uma compreensão do "significado" da teoria social habermasiana para a teoria do direito ou ainda uma "teoria habermasiana do direito". Isto por algumas circunstâncias importantes, já esboçadas no parágrafo anterior.

Em primeiro lugar, Habermas não tem uma teoria do direito no sentido usual e sistemático da locução, isto é, o de uma elaboração teórica acabada, unívoca e operativa que se proponha a explicar o significado valorativo ou a função conceitual do direito, ou que se lance a expor aos agentes inseridos na prática jurídica quais os sentidos mais adequados daquela atividade, e como é possível compreendê-la em uma chave lógica e sistemática. ${ }^{4}$

Em segundo lugar, Habermas jamais se propôs a estudar "o direito" como objeto apartado de uma teoria da sociedade mais ampla, ainda que o direito tenha uma relevância crucial em suas obras, especialmente a partir da publicação de "Facticidade e validade", em 1992. Sempre que se aproximou do direito, Habermas o fez como se acercando de um fenômeno relevante à apreensão ampla da própria sociedade, de seu diagnóstico crítico e das possibilidades daí emergentes de emancipação. Isso impõe um

3 O conceito de "reconstrução" é central ao projeto habermasiano de teoria social. Como apontam Marcos Nobre e Luiz Repa, a reconstrução e o diagnóstico crítico são operações metacomplementares que, não podendo ser individualmente decompostas e singularizadas, remetem, ambas, à "teoria reconstrutiva da sociedade", que assume o papel de esquema teórico e programa metodológico central da teoria de Habermas. Afirmam os autores que "desde pelo menos o início dos anos 1970, Habermas considera que sua teoria crítica da sociedade consiste em uma 'teoria reconstrutiva da sociedade'. Todo o percurso intelectual de Habermas, a partir de então até os seus últimos escritos, é caracterizado pela centralidade da ideia de 'reconstrução'. Trata-se de um operador teórico que permite realizar as duas tarefas fundamentais da teoria crítica: identificar os potenciais de emancipação inscritos na realidade social presente, ao mesmo tempo em que critica e incorpora os resultados das teorias sociais não críticas, das teorias tradicionais. Isso quer dizer também que há uma estreita colaboração entre os procedimentos reconstrutivos e a apresentação de um diagnóstico do tempo presente". (NOBRE; REPA, 2012, p. 7, grifo nosso).

4 Esses dois sentidos de "teoria do direito" correspondem, respectivamente, ao que Michel Troper (2008) denomina de "teoria do direito dos filósofos" (ou "filosofia do direito") e "teoria do direito dos juristas" (ou simplesmente "teoria do direito"). Sinteticamente, a primeira teria por objeto a análise do significado e do valor do direito tomado como objeto externo, enquanto a segunda teria como foco a prática jurídica como esta se apresenta na realidade dos agentes nela inseridos. 
cuidado na utilização, pela teoria jurídica, da obra de Habermas, no sentido de não a compreender como o que ela não é, ou seja, como uma suposta "teoria do direito", seja em sua dimensão descritiva (o que o direito é), seja em sua dimensão normativa (o que o direito deve ou deveria ser). ${ }^{5}$

Em terceiro lugar, a teoria habermasiana não tem um significado homogêneo para a teoria do direito, ou seja, não pode ser compreendida como "uma contribuição" dentre outras para a compreensão teórica do fenômeno jurídico. Isto porque, se não bastasse o que já se disse até aqui, no sentido de que jamais a teoria social de Habermas se enxergou como possuidora do propósito de fazer essa suposta "contribuição", não há, na obra do autor, uma perspectiva do direito que seja unívoca, definitiva ou preponderante. É evidente que essa terceira característica depende das duas anteriores: ora, se Habermas nunca se propôs a teorizar o direito em específico, ou seja, no desengate de sua autoprodução social, como salientou-se na primeira ressalva, é um evidente nonsense procurar em sua obra uma "teoria do direito" (segunda ressalva), tornando obviamente inexistente uma visão homogênea do direito na observação social habermasiana (terceira ressalva). O direito vai aparecer, nas pesquisas de Habermas, como parte de quadros abrangentes de diagnóstico crítico e reconstrução social, assumindo, ele mesmo, silhuetas diferentes conforme o aspecto da produção da práxis social que esteja em questão (sentido habermasiano de "reconstrução"). Daí as descontinuidades que existirão, por exemplo, nas análises que Habermas traça sobre aspectos como o sistema jurídico, o poder administrativo e a constituição. Não há incoerência (cobrar esse tipo de coerência seria incorrer nas falhas apontados nestas três ressalvas, exigindo do autor uma teoria do direito unívoca, sistemática e homogênea), nem propriamente ruptura, na medida em que não exista compromisso, assumido pelo autor, com a invariabilidade linear entre os aspectos da autoprodução social que analisa particularmente nas diferentes fases de suas obras.

Por fim, em quarto lugar, algo que foi em grande parte antecipado acima, a "obra" de Habermas não tem, em si, um caráter necessariamente contínuo. Sua

\footnotetext{
É importante frisar aqui que essa divisão entre uma teoria descritiva e uma teoria normativa não coincide com a distinção, apresentada acima, entre "teoria do direito dos filósofos" e "teoria do direito dos juristas". A "teoria do direito dos filósofos", de acordo com Troper, ainda que tenda a contemplar viés preponderantemente normativo, na medida em que se interroga sobre o "significado do direito", pode ser descritiva (descrição desse significado) ou normativa (predição de um significado). Do mesmo modo, a "teoria do direito dos juristas", ainda que tenda a ser dominada por elementos mais diretamente descritivos (pois visa à orientação dos agentes no interior de uma prática jurídica como esta efetivamente se apresenta), pode ser voltada tanto a um escopo propriamente descritivo (descrição da prática jurídica, visando ao seu enquadramento dentro de um esquema lógico sistemático compreensível), como a um escopo mais normativo (predição de como a prática jurídica deve acontecer, caso emblemático da chamada "doutrina jurídica").
} 
unidade repousa, enquanto bem filiada que é a teoria crítica, no problema do processo de produção (social) da totalidade da práxis social, em clara oposição à alternativa, ensejadora de parcialidade, de hipóstase do conhecimento pela extração de processos parciais da totalidade dessa mesma práxis social geral, a partir da compreensão do objeto como sinopse de facticidades sensíveis a serem simplesmente aceitas, como se não dependessem, não trouxessem a marca, do processo histórico de produção da vida social (HORKHEIMER, 1975, p. 132-133). Desse modo, Habermas não está comprometido com a linearidade de seu objeto de estudo como se o pressupusesse como um continuum a-histórico dotado de "propriedades imutáveis". Pelo contrário, interessam-lhe aspectos intrinsecamente mutáveis da práxis social, que, de maneira esperável, serão objeto de constante combinação e recombinação nos processos de produção dessa mesma práxis. Consequentemente, tais aspectos serão objeto de processos de apropriação e reconstrução variáveis no tempo - e, por isso mesmo, processos tendencialmente descontínuos entre si - por parte do teórico social. Dito de outra maneira, supor a premissa da historicidade da produção da práxis social resulta em admitir a variabilidade de combinação de aspectos inscritos nessa mesma práxis para sua autoprodução, o que resulta, no plano teórico, na abertura à descontinuidade entre diagnósticos críticos e reconstrutivos apoiados nesta práxis, que lhes constitui o substrato.

Fixadas essas quatro ressalvas metodológicas fundamentais, pertinentes ao tipo de pesquisa que este artigo mobiliza, pretende-se agora cruzá-las como referenciais teóricos à hipótese que aqui se investiga, e ao percurso metodológico (o "fio condutor") que se procurará seguir.

\section{Hipótese e fio condutor}

A hipótese é a de que o direito ocupado com a regulação do poder administrativo assume, consoante a leitura habermasiana, a forma de um aspecto da práxis social geral, que, como tal, muda de acordo com o processo de produção dessa práxis que é especificamente analisado. Trazendo para cá o que tracei há pouco em termos de consideração metodológica, o resultado do mapeamento dessa mudança será a identificação de que o deslocamento, realizado por Habermas, em torno do aspecto da práxis total precipuamente observado implica a emergência de um novo diagnóstico, que não necessariamente antagoniza ou invalida o anterior, mas que abre possibilidades a um novo diagnóstico, capaz de identificar novos potenciais de emancipação até então não observados.

Isso não significa dizer que se pretenda, aqui, enfatizar uma "ruptura" na leitura que Habermas faz do direito - até porque, em atenção à terceira ressalva, falar em uma ruptura nesse sentido seria equivocado. O que se quer enfatizar é que o direito 
relativo ao poder administrativo tem seu diagnóstico essencialmente renovado no interior da obra habermasiana, expondo flancos no qual o papel do direito na produção da práxis social pode ser algo além de mero instrumento de atuação e replicação do poder administrativo, sendo relevante a um projeto mais amplo de emancipação ancorado comunicativamente. Isto porque, nos termos do próprio Habermas, "o conceito de poder comunicativo requer uma diferenciação no conceito de poder político", que, abrangendo os "usos do poder administrativo no interior do sistema político", conduz à "proposição de uma perspectiva do direito como o meio no qual o poder comunicativo é traduzido em poder administrativo". (HABERMAS, 1996a, p. 150).

A consequência da leitura como aqui a proponho é a rejeição de uma compreensão "segmentada no tempo" da obra de Habermas. Essa abordagem é especialmente difundida nos cursos de direito, mas também possui repercussão nas ciências sociais. Ela joga com uma dualidade artificial entre algo como uma "primeira fase", verdadeiramente "crítica", de Habermas, contraposta a um segundo momento em que se teria esgotado seu potencial crítico, e predominariam elementos exclusivamente normativos. O custo dessa leitura é estressar uma divisão que não existe. Em momento algum houve algo, no interior da obra de Habermas, minimamente parecido com o aludido rompimento. Vislumbrar uma ruptura nesses termos resultaria em uma inadequada perda de vista da unidade da obra do autor enquanto teoria crítica da sociedade, na qual a reconstrução, operador teórico intrinsecamente dinâmico, desempenha papel nuclear. O próprio Habermas reivindica a unidade mais ampla de sua obra no prefácio de "Facticidade e validade", onde afirma:

After the collapse of state socialism and the end of the "global civil war," the theoretical error of the defeated party is there for all to see: it mistook the socialist project for the design - and violent implementation - of a concrete form of life. If, however, one conceives "socialism" as the set of necessary conditions for emancipated forms of life about which the participants themselves must first reach an understanding, then one will recognize that the democratic self-organization of a legal community constitutes the normative core of this project as well. (...) Even in established democracies, the existing institutions of freedom are no longer above challenge, although here the populations seem to press for more democracy rather than less. I suspect, however, that the unrest has a still deeper source, namely, the sense that in the age of a completely secularized politics, the rule of law cannot be had or maintained without radical democracy. The present investigation aims to work this hunch into an insight. In the final analysis, private legal subjects cannot come to enjoy equal individual liberties if they do not themselves, in the common exercise of their 
political autonomy, achieve clarity about justified interests and standards. They themselves must agree on the relevant aspects under which equals should be treated equally and unequals unequally. (HABERMAS, 1996a, p. xli-xlii, grifo do autor).

O que Habermas afirma, aqui, é exatamente o potencial emancipatório que a análise enfeixada por seu estudo do direito ("Rule of Law") e da imprescindibilidade da legitimidade democrática para seu exercício, dão continuidade ao empreendimento emancipatório proposto pelo "socialismo", entendido como expediente destinado a entabular o conjunto das condições necessárias para a emancipação das formas de vida concretas. Essas condições só podem desempenhar papel político conforme percebidas pelos agentes concernidos, e reivindicadas por eles no exercício de sua autonomia política, membros que são de uma comunidade politicamente organizada em direito. ${ }^{6}$ Esse é o sentido da tese da "democracia radical" que emerge na modernidade, especialmente com as teorizações assumidas na filosofia política de inspiração rousseauniana. É nesse quadro que a teoria crítica proposta por Habermas se vê como continuadora de um projeto inacabado emergente no iluminismo. Assim, a análise do potencial do direito "legítimo" como meio da democracia radical, ao menos no programa teórico do autor, não rompe, e sim completa, o percurso habermasiano iniciado com o diagnóstico da instrumentalização do direito pelo poder administrativo, canalizado pela "juridificação" como mecanismo colonizatório do sistema jurídico sobre o mundo da vida. ${ }^{7}$

Nesse sentido, o capítulo IV de "Facticidade e validade" - no qual Habermas completa seu "enfoque reconstrutivo sobre o direito", 8 analisando, a partir das premissas de desenvolvimento da teoria do direito delineadas no capítulo III, os "princípios do Estado constitucional" - representa uma âncora bastante significativa no mapeamento da emergência desse novo diagnóstico quanto às potencialidades do direito regulador do poder administrativo - poderíamos dizer, do "direito da administração". E isso tanto pela clareza com que Habermas mapeia ali as características-chave desse diagnóstico, permitindo não só a análise de seu significado abstrato, mas fundamentalmente de seu sentido histórico, especialmente se tomado em cotejo com as linhas mestras do diagnóstico então afirmado, quanto pela maneira como Habermas pontua os elementos sociais que guiam o seu deslocamento do foco em relação ao modelo anterior, abrindo

\footnotetext{
6 Para uma análise detida deste ponto, baseada na superação do paradigma da produção pelo tipo de socialismo proposto por Habermas a partir do paradigma comunicativo, e de seu significado para a elaboração de uma teoria crítica da política e da democracia v. Melo (2013, p. 23-41).

7 Com base nesse diagnóstico inicial - que, repise-se, não fica invalidado com a emergência daquele de "Facticidade e validade" - com mais detalhe no próximo tópico deste artigo.

8 "a reconstrutive approach to Law", na locução da edição norte-americana.
} 
novas perspectivas de diagnóstico que levantam novas potencialidades emancipatórias. Tal é o caso, por exemplo, da consideração do caráter constitutivo da realidade social assumido pelo direito, e da perspectiva da constituição como alicerce viabilizador de um projeto radical de autodeterminação democrática.

Dessa maneira, enquadrado o capítulo IV como norte na condução deste artigo, eu gostaria de propor o seguinte desenvolvimento metodológico. No próximo tópico, examino brevemente a perspectiva teórica habermasiana que, com a oposição entre poder administrativo e ação comunicativa, afirma a instrumentalidade do direito público à pretensão colonizadora dos sistemas político e jurídico sobre o mundo da vida (diagnóstico da juridificação). Neste tópico, o capítulo IV funcionará como índice de leitura da obra anterior de Habermas. Em seguida, abordam-se os principais componentes conceituais do novo diagnóstico acerca do direito da administração pública, no qual Habermas enfatiza a constitucionalidade do direito público ao potencial que o mundo da vida tem de criar espaços de comunicação racional em oposição à pretensão instrumental e reificante do sistema jurídico e do poder administrativo (diagnóstico da constitucionalização). Neste tópico, o capítulo IV funcionará como repositório básico dos eixos que veiculam tais componentes. Por fim, no tópico conclusivo, abordo a permanência do caráter propriamente "crítico" na teorização habermasiana nos dois diagnósticos, argumentando que a continuidade entre ambos se encontra na pretensão de legitimidade do direito ocupado em regular o poder administrativo.

4. A instrumentalidade do poder administrativo e a juridificação como forma de colonização do mundo da vida

O diagnóstico da juridificação, cuja versão mais esquemática pode ser lida na "Teoria do agir comunicativo", repousa em uma diferença fundamental entre os "sistemas" e o "mundo da vida". Essa diferença repousa na ambiguidade da produção do trabalho social, tal como desenvolvida na sociedade moderna. A percepção dessa diferença remonta à identificação, feita por Marx, do duplo caráter da mercadoria, que está baseada na ambiguidade do trabalho como, simultaneamente, categoria de significado lastreada na interação social, e processo de abstração calcado no valor de troca. É essa abstração que consubstancia uma racionalidade instrumental, que se impõe sobre a interação social proporcionada pelo trabalho social (racionalidade comunicativa). Habermas afirma que a obra de Marx contém:

um lance genial que tem a ver com a análise da forma da mercadoria. Pela análise do caráter duplo da mercadoria, Marx conseguiu formular os princípios da teoria valor, que permite descrever o processo de desenvolvimento das sociedades capitalistas em uma dupla perspectiva: na 
perspectiva econômica do observador, como processo de autoaproveitamento do capital, que se desdobra em meio a crises; e na perspectiva histórica dos interessados (ou participantes virtuais), como interação conflituosa entre classes sociais. Nos conceitos da teoria do valor, é possível explicar a relação de troca entre força de trabalho e capital varável - institucionalizada no contrato de trabalho e fundamental para o modo de produção - como mecanismo de controle de um processo de reprodução autorregulado e como relação reflexiva que permite entender o processo de acumulação como um processo de regulação anônima. (HABERMAS, 2012, p. 602, grifo do autor).

A partir dessa premissa, Habermas deriva tal ambiguidade em dois tipos de racionalidade: a instrumental, predominante no campo do trabalho abstrato, isto é, aquele que, assumindo a forma de um processo de reprodução autorregulada, é indiferente ao seu objeto, ao caráter da atividade, ao indivíduo trabalhador e à sua situação social (HABERMAS, 2012, p. 604), e a comunicativa, que se reflete na autocompreensão reflexiva da modernidade, conferindo uma lógica interna contrária a instrumentalização do mundo da vida provocada pela dinâmica própria de sistemas que se tornaram autônomos. Essa resistência aos sistemas é operada pelos três padrões de interação do mundo da vida: reprodução cultural, integração social e socialização (HABERMAS, 2012, p. 603).

A razão instrumental pressiona que a racionalidade de sujeitos se amplie sistemicamente, constituindo uma racionalidade teleológica de ordem superior na qual "os imperativos ultrapassam a consciência dos membros que se integram nela” (HABERMAS, 2012, p. 600). Esse mecanismo - operado pela racionalidade instrumental - de abstração e de indiferença culmina na formação de sistemas especializados infensos à consciência e à interação social, o que produz consequências reificantes. Tudo se torna mercadoria, objeto de consumo instrumental, por meio da mediatização do mundo da vida pelos sistemas. É esse processo de mediatização que Habermas denominará “colonização”. A racionalidade instrumental, generalizada em sistemas, coloniza o mundo da vida, espaço da racionalidade comunicativa, por meio da imposição de seu padrão teleológico abstrato e indiferente (daí reificante) sobre os padrões de interação do mundo da vida. ${ }^{9}$ Habermas reforça o caráter especialmente reificante desse mecanismo salientando que:

Uma boa proposta de esquematização desse processo - central à obra habermasiana como um todo encontra-se na interpretação que dele faz Anthony Giddens. De acordo com ele: "A influência da Dialectic of Enlightenment de Adorno e Horkheimer sobre o pensamento de Habermas é, nesse ponto, evidente. Sua 'crítica da razão instrumental' tinha uma convergência direta com a direção política central dos escritos de Habermas (na qual a influência de Max Weber também se fazia sentir em grande medida): a tese do controle crescente sobre a natureza ou sobre as forças de produção não era absolutamente coincidente com a libertação da dominação. (...) O trabalho foi equacionado como 'ação racional orientada por motivos' (Zweckrationalität), que se refere, afirmou Habermas, 'à ação instrumental (...)'. A ação instrumental era 
Marx explica tal processo de abstração real levando à objetivação de contextos de ação integrados socialmente, a qual tem lugar quando as interações já não são coordenadas por normas e valores, nem por processos de entendimento, mas sim por meio de 'valor de troca'. Neste caso, os participantes estão interessados, em primeira linha, nas consequências de seu agir. E à medida que se orientam por 'valores' num sentido racional-teleológico, como se estes fossem objetos de segunda natureza, eles assumem uma perspectiva objetivadora em relação a si mesmos e em relação aos outros, transformando relações sociais e intrapsíquicas em relações instrumentais. Nesse sentido, a transformação do trabalho concreto em trabalho abstrato equivale a um processo de reificação da vida social e da particular. (HABERMAS, 2012, p. 605).

O direito, enquanto veículo de formalização das relações sociais, seria justamente um elemento-chave nesse processo de abstração com consequências reificantes. É a tese habermasiana da juridificação como instrumento da colonização do mundo da vida pelos sistemas funcionais, em especial, pelo sistema do poder administrativo (burocracia estatal) e pelo sistema econômico (monetarização). Com efeito, de acordo com Habermas:

Caso concordemos com a ideia de que a reprodução simbólica do mundo da vida não pode ser transladada para os fundamentos da integração via sistema sem a ocorrência de efeitos colaterais patológicos, e caso essa tendência constitua um efeito colateral inevitável de um arranjo bem sucedido do Estado social, teria de haver (nas esferas da reprodução cultural, da integração social e da socialização) uma adaptação a esferas de ação organizadas formalmente. No nosso entender, as relações sociais organizadas formalmente se constituem nas formas do direito moderno. Por isso, é de se esperar que a passagem da integração social

uma ação orientada por normas técnicas e estava fundada no conhecimento empírico. As regras técnicas envolvidas na ação racional orientada por motivos seriam formuladas com base nos poderes de predição que elas possibilitam. (...) A ação comunicativa estaria baseada na comunicação pela linguagem comum e dependeria da compreensão mútua dos símbolos sociais. (...) Os dois tipos de ação, prosseguia Habermas, poderiam oferecer uma base para distinguir setores institucionais diferentes da sociedade. Havia alguns setores, entre os quais ele incluiu o Estado e o sistema econômico, em que prevalecia a ação racional orientada por motivos. Havia outros, tais como a família ou as relações de amizade, nos quais as 'regras morais da interação' seriam predominantes. Essa classificação também poderia ser adotada, tal como Habermas acreditava, para iluminar a totalidade dos padrões no desenvolvimento das sociedades. Nas sociedades tradicionais ou pré-capitalistas, o âmbito dos subsistemas da ação racional orientada por motivos permaneceu confinado pela autoridade insinuante das estruturas da interação moralmente interligadas. A sociedade capitalista, pelo contrário, seria uma sociedade na qual a expansão dos subsistemas da ação racional orientada por motivos tinha sido privilegiada (em primeiro lugar, na forma pela qual se estabelecia no interior da reprodução ampliada do capital) e, progressivamente, atuava no sentido de erodir as outras formas institucionais". (GIDDENS, 2011, p. 300-302, grifo nosso). 
para a integração sistêmica assuma a figura de processos de juridificação. $\mathrm{E}$ os previsiveis efeitos de reificação teriam de ser analisáveis nesse nível - mais precisamente, como consequência sintomática de determinado tipo de juridificação. (HABERMAS, 2012, p. 641, grifo do autor, grifo nosso).

Dessa maneira, o direito assume o caráter de um mecanismo reificante que permite a ancoragem da racionalidade instrumental típica dos sistemas nos padrões de interação do mundo da vida, mas uma ancoragem desde logo comprometida com o projeto colonizatório, uma vez que a formalização das relações sociais é passo necessário à sua abstração formal e, assim, à erosão da racionalidade comunicativa pelos sistemas funcionais. Isto porque a ancoragem se dá sempre na forma de meios de comunicação simbolicamente generalizados (como o "poder" no caso do sistema do poder administrativo, e o "dinheiro" no caso do sistema econômico monetarizado), já que o mundo da vida é tomado como o espaço da interação comunicativa em torno de significados simbolicamente articuláveis. Entretanto - e de modo decisivo - esse tipo de generalização está a serviço da racionalidade instrumental sistêmica, na medida em que representa a viabilização, no mundo da vida, da possibilidade de ação instrumental, infiltrando-a neste domínio outrora regido pelos padrões da racionalidade comunicativa. Em última análise, a função desse tipo de generalização é a criação de condições de legitimação da ação instrumental no mundo da vida, e, com isso, da sua própria colonização pelos sistemas (HABERMAS, 2012, p. 645).

O caso da juridificação do poder administrativo é, nesse sentido, emblemático. Ficam minadas as possibilidades de desenvolvimento de uma racionalidade comunicativa em termos do exercício do poder administrativo, pois essas possibilidades se encontram neutralizadas pela generalização comunicativa do meio "poder" no mundo da vida, que passa a ser regido, pois, pela ação instrumental da disputa pelo poder. O direito público, dessa maneira, ao garantir a abstração do meio "poder" em relações jurídicas formais, sela a colonização do mundo da vida pelo sistema do poder administrativo:

o direito público autoriza um poder soberano do Estado que dispõe do monopólio do poder como única fonte do poder legal. O soberano não está obrigado a se orientar por certos conteúdos ou fins do Estado, pois ele é definido de forma instrumental, isto é, somente em relação aos meios do exercício legal de um poder organizado burocraticamente. O meio da alocação efetiva do poder se transforma no fim único. (HABERMAS, 2012, p. 643, grifo nosso).

O que se observa é, portanto, que a juridificação do sistema do poder administrativo, na forma de direito público, induz, dentro de seu quadro colonizatório sobre o mundo da vida, uma perspectiva estritamente instrumental do poder. A ação 
com relação ao poder administrativo fica, assim, inteiramente sob o domínio da razão instrumental, onde assume a forma de uma disputa pelo exercício de um poder soberano enquanto realidade onipotente previamente constituída (HABERMAS, 2012, p. 649).

Estritamente instrumental, o exercício do poder é, de forma paralela ao que ocorre com relação à sua disputa, visto de um ângulo puramente formal, sendo relevante apenas a autorização jurídica abstrata do Estado soberano a que o mesmo Estado soberano atue. Daí a centralidade do conceito de "competência" no direito público. Não há, aqui, qualquer vinculação do Estado a um conteúdo identificado a ele para além de seu próprio poder soberano. Há apenas sua autovinculação a um regime formal de direito público, que trabalha necessariamente na chave das "competências e prerrogativas da soberania", normas formais que se restringem a "instrumentalizar", "autorizar", "viabilizar" e "limitar" o exercício do poder, que, insista-se, permanece, em si, bloqueado à ação comunicativa baseada na efetiva interação social.

A juridificação produz, assim, uma silhueta de direito público que existe apenas como meio simbolicamente generalizado de instrumentalidade do poder administrativo. Indicativa dessa perspectiva é a ideia, generalizada na teoria jurídica brasileira, de que a função do direito público é "limitar o poder". O custo de contentarse com isso repousa na circunstância de que esse poder "limitado" permanece, todavia, insondável à sociedade comunicativamente organizada. A esfera pública não tem nada a dizer quer em relação à constituição desse poder, quer em relação ao seu efetivo exercício.

5. O potencial de conversão do poder comunicativo em poder administrativo e a dimensão constituinte do direito público

No diagnóstico esboçado no item anterior, o Estado constitucional não tem como assumir qualquer papel que não seja o de ficção, na medida em que a esfera pública não possa ser identificada a processos reais de interação social entre os agentes que constituem o público. Sua função é garantir a instrumentalização em torno do poder, neutralizando o sistema político-administrativo da ação comunicativa, no quadro de um processo de colonização deste sistema sobre o mundo da vida.

Esse diagnóstico começa a assistir, contudo, a emergência de outro, que não o desconfirma, mas que guarda certo grau de descontinuidade com relação a ele, por apoiar-se exatamente na percepção do esgotamento das energias que davam suporte à utopia ligada à sociedade do trabalho, que era a sede de produção da práxis social a que o primeiro diagnóstico se propunha a enfrentar do ponto de vista teórico. Esse esgotamento se teria processado exatamente pela perda do ponto de referência dessa utopia na realidade, devido ao enfraquecimento da "força formadora de estruturas e constituidora da sociedade própria do trabalho abstrato" (HABERMAS, 2015, p. 216), constatação 
que anima Habermas a proceder a uma revisão do equilíbrio até então estabelecido entre poder administrativo, direito e mundo da vida, equilíbrio este que culminava, como já salientado, nos diagnósticos da colonização e da juridificação.

Habermas passa, então, a trabalhar com a hipótese de que a perda objetiva da centralidade da categoria do trabalho abstrato na formação e na constituição da sociedade tem o potencial de ameaçar as barreiras, convergentes no Estado de bem-estar social, com as quais o sistema do poder administrativo e o sistema econômico neutralizavam instrumentalmente o potencial de conflito inscrito no status de trabalhador assalariado (HABERMAS, 2015, p. 218-219). Essas barreiras, por sua vez, eram baseadas em compensações recíprocas realizadas a partir dos meios de comunicação simbolicamente generalizados, como o poder e o dinheiro. Trabalho por dinheiro, dinheiro por poder, trabalho por poder. Nesse sentido, a dominação do sistema do poder administrativo sobre o indivíduo, forçando-o a assumir a posição de cliente passivo da burocracia administrativa, era compensado pelos direitos subjetivos a ele outorgados pelo próprio Estado, em face do qual ele poderia exercer sua pretensão jurídica no sentido de exigir que tais direitos lhe fossem coercitivamente efetivados. A dominação do sistema econômico, que torna o indivíduo consumidor de bens em massa, era, por sua vez, compensada pelo poder de compra, viabilizado pelo trabalho assalariado (HABERMAS, 2015, p. 219).

O que importa reter, contudo, é que a partir da consideração do esgotamento da utopia vinculada à categoria do trabalho, Habermas nota que este mecanismo de neutralização das pretensões comunicativas - operado pela colonização sistêmica, que, jogando com meios de comunicação como poder e dinheiro, visa produzir, no mundo da vida, a legitimação da ação instrumental - acaba seriamente comprometido, por sua dependência da neutralização do potencial crítico inscrito no trabalho assalariado, em um contexto em que essa categoria-chave - a do trabalho salariado - não se encontra mais apta a exercer esse papel neutralizador-compensatório, em função da própria derrocada mais ampla da utopia do trabalho como categoria central à produção da práxis social. $\mathrm{O}$ esgarçamento dessas barreiras de neutralização, que constituíam a base da legitimidade do Estado de bem-estar social, abre espaço, então, para uma reconstrução do problema da legitimação jurídica no Estado contemporâneo, em que a esfera da solidariedade, associada ao mundo da vida, desempenha papel privilegiado na confrontação das esferas sistêmicas:

As sociedades modernas dispõem de três recursos a partir dos quais podem satisfazer sua necessidade de operações de controle: dinheiro, poder e solidariedade. Suas esferas de influência deveriam ser colocadas em um novo equilíbrio. Com isso, eu quero dizer: o poder de integração social da solidariedade deveria ser capaz de afirmar-se contra os 'poderes' dos outros dois recursos de controle, 
dinheiro e poder administrativo. Ora, os âmbitos da vida especializados em dar continuidade aos valores transmitidos e ao saber cultural, em integrar grupos e socializar crianças e adolescentes dependem da solidariedade. (HABERMAS, 2015, p. 233).

Isto significa que a derrocada da utopia do trabalho enquanto força constituidora e estruturante da sociedade abre espaço para um reequilíbrio entre os padrões característicos do mundo da vida (reprodução cultural, integração social e socialização) e os meios de colonização do mundo da vida oriundos dos sistemas (no caso, dinheiro e poder administrativo), possibilitando uma afirmação da razão comunicativa contra o agir instrumental, invertendo o sentido da colonização sistêmica. Habermas prossegue, e, no mesmo parágrafo, expõe o que imagina como condição desse processo de inversão:

Porém, teria de beber da mesma fonte uma formação política da vontade que deve ter influência sobre o traçado de limites e o intercâmbio entre esses âmbitos da vida comunicativamente estruturados, por um lado, e o Estado e a economia, por outro. Aliás, isso não se situa muito longe das ideias normativas de nossos manuais de instrução cívica, segundo os quais a sociedade influi sobre si mesma e sobre seu desenvolvimento através da dominação democraticamente legitimada. (HABERMAS, 2015, p. 233).

A condição desse reequilíbrio é, portanto, que o domínio da razão comunicativa possa determinar a ação instrumental dos sistemas, adquirindo por consequência a capacidade de efetivamente influir sobre sua própria constituição e seu desenvolvimento. Nesse processo de inversão do fluxo colonizatório, a retração da legitimação instrumental baseada no poder administrativo e no dinheiro deixa um vácuo que precisa ser preenchido por algum mecanismo de legitimidade, formado, dessa vez, sob o influxo decisivo da razão comunicativa.

Essa legitimidade, aponta Habermas, está inscrita no próprio projeto da modernidade, cujo potencial teria sido sufocado pela dominação instrumental. ${ }^{10}$ Trata-

10 Habermas já havia reconhecido esse potencial, aberto pela modernidade, de exercício comunicativamente reflexivo do poder, porém, em seu diagnóstico inicial, este potencial vinha completamente sufocado pela instrumentalização em torno do poder administrativo como meio de sua legitimação. Como o autor aponta em "Mudança estrutural da esfera pública": "The political public sphere of the social-welfare state is marked by two competing tendencies. Insofar as it represents the collapse of the public sphere of civil society, it makes room for a staged and manipulative publicity displayed by organizations over the heads of a mediatized public. On the other hand, to the degree to which it preserves de continuity with the liberal constitutional state, the social-welfare state clings to the mandate of a political public sphere according to which the public is to set in motion a critical process of public communication through the very organizations that mediatize it. In the constitutional reality of the social-welfare state this form of critical publicity is in 
se do ideal tipicamente moderno de "dominação democraticamente legitimada", que funciona, aqui, como potencial vetor de controle da sociedade comunicativamente articulada sobre sua própria constituição e seu desenvolvimento. Em outras palavras, o esgotamento da utopia do trabalho permite um desequilíbrio da legitimação instrumental, abrindo espaço para a reabilitação do projeto moderno de soberania do povo a partir da dominação democraticamente legitimada.

Esse passo argumentativo é fundamental porque permite que se identifique como estão ligados, por um lado, a agenda de pesquisa em torno de novas potencialidades de legitimação - e do papel do direito em estruturá-las - abertas com a crise do trabalho enquanto categoria central de autoprodução da sociedade, e, por outro lado, a reconstrução habermasiana da teoria da soberania popular, que atribui à democracia o papel juridicamente mediatizado de controle comunicativo da autoprodução social, garantindo que sua constituição e seu desenvolvimento se pautem pelo direito democraticamente legitimado.

São essas duas direções que irão se combinar para produzir a reconstrução que resulta em "Facticidade e validade", e, no caso específico de seu capítulo IV, do direito do poder administrativo enquanto instituição do Estado constitucional, reconstrução que já havia sido, em vários aspectos, antecipada com a publicação de "Soberania popular como processo", posteriormente reeditado como anexo de "Facticidade e validade".

Assumindo a hipótese de que o capítulo IV de "Facticidade e validade" contém uma sistematização consistente da nova reconstrução operada por Habermas acerca da relação entre poder administrativo e direito, há que se identificar dois pilares fundamentais da argumentação ali desenvolvida pelo autor.

O primeiro é a compreensão de que o direito possui uma dimensão constitutiva, que não se esgota na mera juridificação a partir de normas gerais e abstratas responsáveis pela organização formal das relações sociais. É dizer: o direito tem algum potencial enquanto veículo comunicativo na criação de uma racionalização a partir da integração social e dos processos de socialização e reprodução cultural, e não apenas

conflict with the publicity merely staged for manipulative ends. The extent to which the former type prevails gauges the degree of democratization of an industrial society constituted as a social-welfare state - namely, the rationalization of the exercise of social and political authority. The state committed to social rights has abandoned the fiction of the liberal constitutional state that with its establishment as an organ of state the public sphere had actually become a reality in the realm of politics. From the very start, indeed, the parliament was rent by the contradiction of being an institution opposing all political authority and yet established as an 'authority' itself. In contrast, publicity operating under the conditions of a social-welfare state must conceive of itself as a self-generating process. Gradually it has to establish itself in competition with that other tendency which, within an immensely expanded public sphere, turns the principle of publicity against itself and thereby reduces its critical efficacy". (HABERMAS, 1991, p. 232-233, grifo do autor). 
formalizar uma relação abstrata, instrumento dos sistemas econômico e político, sobre a integração social e os padrões de socialização e reprodução cultural.

O segundo pilar argumentativo se apoia na possibilidade de uma identificação entre poder político e poder comunicativo, este último que, viabilizado pelo direito do Estado constitucional, poderia ser traduzido em poder administrativo. É dizer: o direito tem algum potencial na conversão do poder comunicativo em poder administrativo, possibilitando o enraizamento do próprio exercício do poder político no espaço de integração social, reprodução cultural e socialização, consubstanciado no domínio da interação social comunicativa (o assim denominado "mundo da vida", em oposição aos sistemas abstratos instrumentais). Esses dois elementos constituirão, aqui, o índice básico por meio do qual se observará a argumentação desenvolvida por Habermas em "Facticidade e validade" e em "Soberania popular como processo" (no qual aparecem, pela primeira vez, muitas das ideias que serão depois desenvolvidas com mais detalhe em "Facticidade e validade"); e, antes, o momento anterior do autor no qual apareciam, com outro enfoque reconstrutivo, os temas do poder administrativo e do direito a ele atinente.

$\mathrm{Na}$ primeira direção, o direito precisará reabilitado, com relação ao diagnóstico da juridificação, em sua potencialidade de constituição de uma sociedade a partir de sua própria articulação comunicativa.

Habermas parte da tese, defendida tanto em "Soberania popular como processo" $" 11$ quanto em "Facticidade e validade", ${ }^{12}$ de que os direitos humanos não

11 Neste artigo, Habermas defende que a soberania popular pode ser pensada como chave para a compreensão da dialética entre liberalismo e democracia radical (p. 472), cujo protótipo teria sido a Revolução Francesa, na qual a articulação de agentes privados, no exercício de sua autonomia, reivindica o poder de participação da formação da vontade soberana do Estado (p. 466). Essa cooriginalidade entre o projeto de autonomia moral privada e o projeto democrático radical de soberania popular garante o equacionamento da dialética entre liberalismo e democracia radical, pois, como afirma Habermas: "Human rights do not compete with popular sovereignty; they are identical with the constitutive conditions of a self-limiting practice of publicly discursive will-formation". (HABERMAS, 1996b, p. 477).

12 De acordo com a argumentação de Habermas no capítulo IV de "Facticidade e validade", "the legitimacy of rights and the legitimation of lawmaking processes are not the only question. There is also the question of the legitimacy of a political order and the legitimation of the exercise of political power. The basic rights reconstructed in our thought experiment are constitutive for every association of free and equal consociates under law; these rights reflect the horizontal association of citizens in statu nascendi, as it were. But the selfreferential act that legally institutionalizes civic autonomy is still incomplete in essential respects; it cannot stabilize itself. The moment of a reciprocal conferral of rights remains a metaphorical event. It can perhaps be recalled and ritualized, but it cannot become permanent unless state power is established and put to work. If the interpenetration of private and public autonomy brought about in the system of rights is to be rendered permanent, then the process of juridification must not limit itself to the liberty of private persons and the communicative freedom of citizens. It must extend immediately to that political power already presupposed with the medium of law, a power to which the making as well as the enforcing of law owe their binding character. The co-original constitution and conceptual interpenetration of law and political power call for a more extensive legitimation, one requiring legal channels for the sanctioning, organizing, and executive powers of the state itself". (HABERMAS, 1996a, p. 132-133, grifo do autor). 
competem com a soberania popular, sendo, ao contrário, cooriginais em relação a ela, ambos identificando-se às condições constitutivas de uma prática autolimitada e publicamente discursiva de formação da vontade política (esfera pública).

Habermas situará o direito como mecanismo de articulação comunicativa privilegiada entre autonomia pública e privada, na formação de um direito que, por seu enraizamento comunicativo nessa esfera pública, tem a aptidão de constituir uma realidade política democraticamente legitimada. Essa aptidão é afirmada por Habermas pela consideração de que o direito não apenas estabelece regras que instrumentalizam o poder. Ao lado desse papel tradicionalmente identificado à juridificação, o direito, especialmente aquele destinado a reger o poder administrativo, possui também um papel fundamental na criação e constituição dos arranjos normativos institucionais no interior dos quais o poder será criado e exercido. Com efeito, do ponto de vista desse potencial constituinte do direito, Habermas considera que:

Only in virtue of this instrumental function of political power are courts transformed into organs of a state. Law thus owes to the state its function of stabilizing behavioral expectations that are generalized in temporal, social, and substantive respects. We therefore distinguish the functions that law and power fulfill for each other from the intrinsic functions the legal and power codes fulfill for society as a whole. (...) The contribution of political power to the intrinsic function of law, hence to the stabilization of behavioral expectations, is to engender a legal certainty that enables the addressees of law to calculate the consequences of their own and others' behavior. From this point of view, legal norms must assume the form of comprehensible, consistent, and precise specifications, which normally are formulated in writing; they must be made known to all addressees, hence be public; they may not claim retroactive validity; and they must regulate the given set of circumstances or "fact situation" in terms of general features and connect these with legal consequences in such a way that they can be applied to all persons and all comparable cases in the same way". These requirements are met by a codification that provides legal rules with a high degree of consistency and conceptual explication. This is the task of a jurisprudence that works through the legal corpus in a rigorous fashion, making it the subject of doctrinal refinement and systematization. The contribution that law makes to the intrinsic function of administrative power, on the other hand, is especially evident in the development of secondary rules in $\mathrm{H}$. L. A. Hart's sense. These include not only power-conferring norms that furnish government institutions with their special jurisdictions or even constitute these institutions to begin with, but also organizational norms that lay down 


\begin{abstract}
procedures according to which legal programs come into being and are dealt with administratively or judicially. Law by no means exhausts itself in behavioral norms but increasingly serves to organize and regulate state power. It functions as a system of constitutive rules that not only guarantee the private and public autonomy of citizens but generate government institutions, procedures, and official powers. (HABERMAS, 1996a, p. 143-144, grifo do autor, grifo nosso).
\end{abstract}

A mobilização que Habermas faz da teoria do direito de Hart não é, portanto, trivial. Normas primárias, definidas por Hart em 1961 como aquelas que estabelecem coercitivamente uma obrigação, dividem espaço, no direito moderno, com as normas

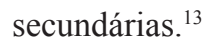

Recapitulando Hart, normas secundárias são normas que tratam das próprias normas primárias, e podem ser de três tipos: (i) normas que dizem respeito ao reconhecimento das normas primárias como emanadas de uma autoridade socialmente vinculante (rule of recognition); (ii) normas que indicam a autoridade responsável pela adjudicação em caso de conflitos em torno de normas primárias (rule of adjudication); e (iii) normas que disciplinam a mutabilidade das normas primárias (rule of change).

Isso significa que existe outra categoria de normas legais para além daquelas que estabelecem obrigações jurídicas (normas primárias), e, no caso específico do direito do poder administrativo, obrigações que instrumentalizam o poder tomado como "dado", conferindo ou limitando seu exercício e sua disputa. Há, portanto, no direito público um potencial permanentemente aberto à variação social em torno de sua própria constituição enquanto "poder".

Significa dizer, o poder em nada se caracteriza, para esse tipo de teoria do direito, como um dado "apriorístico" ou "natural", mas sim como um objeto constituído juridicamente, e, assim, permanentemente aberto à contingência (indeterminação como meio de variação). A filiação do argumento de Habermas não é, assim, casual. A obra de Hart - expoente da teoria jurídica liberal democrática - é inteiramente construída para responder a uma demanda moral central segundo a qual o modo de ser do direito deve estar sempre aberto à crítica e à mudança social (MACCORMICK, 2009, p. 42).

O que é preciso mobilizar dessa reconstrução de Hart é que Habermas passa a enxergar, aqui, que o direito tem a possibilidade de "organizar o exercício do poder político", assumindo, portanto, o potencial de ser canal da inversão do fluxo da colonização, garantindo o "cerco" comunicativo dos sistemas funcionalmente diferenciados, que precisarão se ajustar a um direito dependente da facticidade do processo democrático:

$\overline{13 \quad \text { Vide Hart (1994), }}$ capítulo 5, tópico 3. 
Communicative power is exercised in the manner of a siege. It influences the premises of judgment and decision making in the political system without intending to conquer the system itself. It thus aims to assert its imperatives in the only language the besieged fortress understands: it takes responsibility for the pool of reasons that administrative power can handle instrumentally but cannot ignore, given its juridical structure. (HABERMAS, 1996b, p. 486-487, grifo nosso).

A esfera pública, enquanto público formado por cidadãos autônomos, tanto em sua dimensão privada (autonomia da vontade política) quanto em sua dimensão pública (participação na interação social discursiva de formação pública da vontade coletiva), ${ }^{14}$ é a medida do enraizamento comunicativo do direito (razão comunicativa). Isso significa que a eticidade do Estado de direito (poder juridicamente organizado) depende decisivamente da factidade do processo democrático que o mantém ancorado no mundo da vida racionalizado, ou seja, que o mantém vinculado ao domínio da interação social comunicativamente articulada:

Constitutional democracy is becoming a project, at once the outcome and the accelerating catalyst of a rationalization of the lifeworld reaching far beyond the political. The sole substantial aim of the project is the gradual improvement of institutionalized procedures of rational collective will-formation, procedures that cannot prejudge the participants' concrete goals. Each step along this path has repercussions on the political culture and forms of life. Conversely, without the support of the sociopolitical culture, which cannot be produced upon demand, the forms of communication adequate to practical reason cannot emerge. (HABERMAS, 1996b, p. 489, grifo nosso).

\footnotetext{
14 A autonomia privada é dada a partir de um sistema de direitos cuja função é a de garantir a autolegislação, predicando a autonomia moral no plano da escolha individual. A autonomia pública designa a participação de agentes privadamente autônomos em uma prática comunicativa de formação pública da vontade coletiva, prática esta que é autolimitada do ponto de vista procedimental-racional (vale dizer, pela interação social concreta e discursivamente articulada). Nos termos que Habermas propõe ao longo do capítulo IV de "Facticidade e validade", "The idea of self-legislation, which implies moral autonomy at the level of the individual will, takes on the meaning of political autonomy at the level of collective will-formation. Political autonomy is not simply a result of applying the discourse principle to a different kind of action norm and giving this principle itself a legal shape with the system of rights. It is not just the legal form alone that distinguishes political from moral self-legislation, but the contingency of the form of life, of the goals and interest positions establishing the identity of the self-determining political will in advance. Although the morally good will is fully absorbed, as it were, into practical reason, even the rationally grounded political will retains a certain contingency insofar as it rests on context dependent reasons. This explains why the common ground of shared beliefs, achieved discursively in different political arenas, also generates communicative power". (HABERMAS, 1996a, p. 157).
} 
Especificamente no caso do direito responsável pela regulação do poder administrativo, o projeto de constitucionalização democrática visa ao incremento de uma racionalidade comunicativa que, dependendo da procedimentalização de mecanismos racionais (necessariamente públicos) de formação da vontade soberana, supera a racionalidade instrumental do poder administrativo, por meio da conjugação do exercício desse poder a procedimentos de criação e controle social impulsionados a partir da interação social do mundo da vida. Como esse tipo de autonomia pública não subsiste sem a autonomia privada que lhe é cooriginal ${ }_{15}^{15}$ nada nessa estrutura de procedimentalização, de "racionalização do mundo da vida", pode ser indiferente ao livre exercício da autonomia por parte dos agentes em interação na esfera pública. Esse fator, no caso do direito do poder administrativo, impede qualquer decisão que não seja fundada no poder comunicativo exercido no plano do mundo da vida racionalizado.

E aqui se encontra a segunda direção fundamental desenvolvida no capítulo IV de "Facticidade e validade", que enfatiza o papel do direito como meio de tradução do poder comunicativo em poder administrativo, o que pressupõe a assunção de que há, no âmbito do poder político, uma dimensão não instrumental, que é justamente aquele espaço por meio do qual é possível o engate do poder político na racionalidade comunicativa. Esse espaço é precisamente o do poder comunicativo:

Arendt conceives political power neither as a potential for
asserting one's own interests or for realizing collective goals,
nor as the administrative power to implement collectively
binding decisions, but rather as an authorizing force
expressed in 'jurisgenesis' - the creation of legitimate law
- and in the founding of institutions. (...) with the concept
of communicative power, we get hold of only the emergence
of political power, not the administrative employment of
already constituted power, that is, the process of exercising
power. Nor does this concept explain the struggle for
access to administrative power. Arendt emphasizes that the
employment of, as well as the competition to acquire and
preserve, power depends on the communicative formation
and renewal of this power. Objecting to sociological
theories that restrict themselves to phenomena of power
allocation and competition for power, she rightly observes
that no political authority can expand the resources of its
power as it wishes. Communicatively produced power is
a scarce resource, which organizations compete for and
officials manage, but which none of them can produce.
(...) The concept of communicative power requires a

15 Sobre o nexo interno entre soberania popular e os sistemas de direitos que garantem a autonomia moral privada, v. Habermas (2001). 
differentiation in the concept of political power. (...) The exercise of political autonomy implies the discursive formation of a common will, not the implementation of the laws issuing therefrom. The concept of the political in its full sense also includes the use of administrative power within the political system, as well as the competition for access to that system. The constitution of a power code implies that an administrative system is steered through authorizations for rendering collectively binding decisions. This leads me to propose that we view law as the medium through which communicative power is translated into administrative power. (...) We can then interpret the idea of the constitutional state in general as the requirement that the administrative system, which is steered through the power code, be tied to the lawmaking communicative power and kept free of illegitimate interventions of social power (i.e., of the factual strength of privileged interests to assert themselves). Administrative power should not reproduce itself on its own terms but should only be permitted to regenerate from the conversion of communicative power. (HABERMAS, 1996a, p. 149-150, grifo do autor, grifo nosso).

Nesse sentido, o poder político não se esgotaria em "poder administrativo". Ele abrangeria também o poder comunicativo, que designa a gênese institucional a partir da conjugação democrática entre autonomia pública e autonomia privada. ${ }^{16}$ Habermas fala então de uma "jurisgenesis" enquanto processo de produção do direito legítimo pela interação comunicativa. Esse poder comunicativo designa, assim, a emergência do poder político enquanto exercício da autonomia na forma do procedimento público de formação da vontade coletiva.

16 Sobre a relação entre essa conjugação e o conceito de esfera pública, Habermas afirma: "This communicative practice bears the burden of stabilizing itself; with each important contribution, public discourse must keep alive both the meaning of an undistorted political public sphere as such and the very goal of democratic will formation. The public sphere thereby continually thematizes itself as it operates, for the existential presuppositions of a nonorganizable practice can be secured only by this practice itself. The institutions of public freedom stand on the shifting ground of the political communication of those who, by using them, at the same time interpret and defend them. The public sphere thus reproduces itself self-referentially, and in doing so reveals the place to which the expectation of a sovereign self-organization of society has withdrawn. The idea of popular sovereignty is thereby desubstantialized. Even the notion that a network of associations could replace the dismissed "body" of the people - that it could occupy the vacant seat of the sovereign, so to speak - is too concrete. This fully dispersed sovereignty is not even embodied in the heads of the associated members. Rather, if one can still speak of "embodiment" at all, then sovereignty is found in those subjectless forms of communication that regulate the flow of discursive opinion- and willformation in such a way that their fallible outcomes have the presumption of practical reason on their side". (HABERMAS, 1996b, p. 486). 
Fica fora do poder comunicativo o poder político em sua dimensão instrumental, representado pelo exercício concreto do poder administrativo e a competição por ele. Ainda assim, esses dois aspectos instrumentais continuam a integrar o poder político, de modo que se coloca a necessidade de haver uma mediatização capaz de traduzir o poder comunicativo em poder administrativo, vinculando a racionalidade instrumental do sistema formado em torno dele à racionalidade não instrumental do poder comunicativo.

Essa mediatização é o direito do poder administrativo, ou simplesmente "direito público", dobradiça ancorada simultaneamente na racionalização do mundo da vida (expressa no poder comunicativo), e no domínio instrumental do poder político (expresso no exercício e na disputa do poder administrativo). A função do direito público, nessa compreensão, é impedir que o poder administrativo se autorreproduza, vinculando-o necessariamente à racionalidade comunicativa encarnada pelo projeto de constitucionalização democrática (constituição jurídica da esfera pública).

O sentido geral da descontinuidade desse equilíbrio com relação àquele da juridificação do Estado de bem-estar social é, portanto, o da superação de uma legitimação calcada na generalização social do meio poder (direito como instrumento), por uma forma de legitimação democrática que subordina o aspecto instrumental do poder político (exercício e disputa do poder administrativo) àquele seu aspecto vinculado à racionalidade comunicativa, assim, ao exercício da autonomia pública e privada dos cidadãos (poder comunicativo). Essa nova forma de legitimação define o novo horizonte do direito do poder administrativo, que, sendo criado pelo poder comunicativo a partir da "jurisgenesis", é responsável por "montar um cerco" à pretensão autolegitimadora do sistema funcional do poder administrativo, garantindo que esse sistema esteja constrangido pela legitimidade democrática. Isso não quer dizer que o poder administrativo tenha perdido sua dimensão instrumental, pois isso seria superar a dualidade sistema/mundo da vida, mas sim que o direito do poder administrativo tem a potencialidade de inverter o fluxo de colonização do sistema do poder administrativo sobre o mundo da vida. O direito deixa de ser mero instrumento do poder, para assumir seu papel na constituição desse poder.

Desse modo, a ideia de "jurisgenesis" é o elemento fundamental da reversão do processo de instrumentalização do direito pela juridificação, pois dá origem a um direito formado não a partir da formalização das relações sociais, mas sim a partir do poder comunicativo, que só existe em interações sociais efetivas, em um espaço normativo autônomo, necessariamente diferente dos interesses privados instrumentais, diferente inclusive dos interesses instrumentais dos eventuais detentores ocasionais do poder administrativo:

The more concrete the matter in need of regulation and the more concrete the character of legal propositions, the 
more the acceptability of norms also expresses the selfunderstanding of a historical form of life, the balance between competing group interests, and an empirically informed choice among alternative goals. The teleological points of view that find their way into legal contents through these volitional components become more pronounced to the extent that a society concentrates the pursuit of collective goals in the state, for this also determines how much the legislature must program the expanded policy fields and growing organizational capacities of the state. Even in the liberal model, in which the pursuit of collective goals is generally moved from the government (restricted to enforcing rights) over to market mechanisms and voluntary associations, law cannot be kept free of the political aims implemented in tax legislation and military protection. At the same time, the consideration of collective goals must not wreck the legal form, and therewith the intrinsic function of law; it must not permit law to be absorbed into politics. Otherwise the tension between facticity and validity, displayed in its pure form in modern law, would have to disappear. (HABERMAS, 1996a, p. 152).

Com efeito, a normatividade do direito que emerge do poder comunicativo não autoriza a dissolução da validade em facticidade, nem o oposto. O exercício do poder administrativo, na dimensão de sua validade jurídica, precisa encontrar sua justificação na facticidade democrática do direito, evitando o que seria a legitimação do poder no próprio poder (como no quadro da juridificação do poder administrativo). Por outro lado, a facticidade da política democrática precisa ser articulada à ação instrumental das esferas de exercício e disputa do poder administrativo, o que impede uma completa absorção da validade pela facticidade democrática.

Em ambos os casos, o direito da administração pública, como mediação entre poder comunicativo e sistema da administração pública, impede tanto a anulação da política pela autolegitimação dos interesses juridificados, quanto a absorção, pela facticidade democrática, da função específica do sistema político de instrumentalmente efetivar pautas programáticas colhidas no mundo da vida. O mundo da vida é, por sua vez, garantido e operacionalizado pelo direito da administração pública na chave da validade jurídica (e da vinculação do poder administrativo à lei, pelo tradicional "princípio da legalidade"). Daí a existência de uma necessária metacomplementaridade, nos Estados democráticos constitucionais contemporâneos, entre poder comunicativo, direito vinculante democraticamente legitimado, e sistema do poder administrativo:

binding law and political power form a complex in which each fulfills a function for the other. At the same time, this complex opens up the possibility that law will be instrumentalized for the strategic deployment of power. To 
counter such instrumentalization, the idea of government by law requires the state apparatus to be organized in such a way that any use of publicly authorized power must be legitimated in terms of legitimately enacted law. Certainly the codes of law and power must always work for each other if each is to fulfill its own function. But these exchange relationships feed on a legitimate lawmaking that, as we have seen, goes hand in hand with the formation of communicative power. As a result, the concept of political power must be carefully differentiated. In the system of public administration, there is concentrated a power that must always regenerate itself a new out of communicative power. Thus the law is not only constitutive for the power code that steers administrative processes. It represents at the same time the medium for transforming communicative power into administrative power. The idea of the constitutional state can therefore be expounded with the aid of principles according to which legitimate law is generated from communicative power and the latter in turn is converted into administrative power via legitimately enacted law. (HABERMAS, 1996a, p. 168169, grifo nosso).

Assim, a silhueta do direito do poder administrativo que se afirma, aqui, pressupõe tanto o esforço feito por Habermas no sentido de reivindicar, para esse direito, uma função constitutiva - naquele movimento que chamei de "primeira direção" do capítulo IV de "Facticidade e validade" - como o esforço subsequente no sentido de

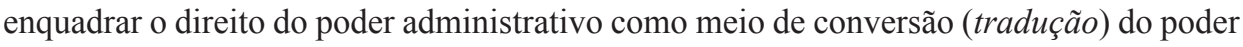
comunicativo em poder administrativo - naquilo que chamei de "segunda direção" do capítulo IV de "Facticidade e validade". A síntese dessas duas direções produz um quadro no qual o direito da administração assume tanto o papel de constituir a autoridade que funciona como referencial da soberania popular no sistema do poder administrativo, possibilitado por seu enraizamento no mundo da vida racionalizado, quanto o papel de traduzir o poder comunicativo em poder administrativo, possibilitado por sua posição como expediente capaz de mediatizar, pela via da validade jurídica (legitimidade), a interação social democrática (facticidade) e a vinculação do sistema do poder administrativo a essa interação factual.

Essa dupla vinculação entre política e direito, que não se limita ao plano de uma relação entre sistemas funcionalmente diferenciados, assume, portanto, a forma de uma relação baseada na unidade do projeto constitucional de racionalização do mundo da vida, e da subsequente expansão da racionalidade comunicativa sobre os sistemas funcionalmente diferenciados. A unidade desse projeto de racionalização acaba por reabilitar o Estado constitucional como referencial normativo da conjunção entre autonomia pública e privada, em uma rede na qual a soberania é desvinculada de um 
órgão de poder, passando a designar os diversos arranjos sociais reflexivos de formação da autoridade pública. Essa soberania assume, pois, a forma de um poder discursivamente articulado pela vontade coletiva de agentes pública e privadamente autônomos.

\section{Breve conclusão}

O saldo das duas reconstruções que Habermas propõe sobre o direito público aponta, não há dúvidas, para a identificação de potenciais emancipatórios na relação entre direito e poder administrativo, potenciais que não se faziam sentir no diagnóstico inicialmente proposto pelo autor. Entretanto, essa constatação não deve ser vista como autorizativa da conclusão de que há a superação de um diagnóstico pelo outro. E isso não apenas pelos motivos metodológicos apontados no segundo item deste trabalho, mas também pelo fato de que as condições que conduziam ao diagnóstico inicial não foram automaticamente eliminadas ou superadas.

No que se refere especificamente ao direito público, o diagnóstico da colonização como processo impulsionado pela juridificação permanece como possibilidade que guarda em si o risco de eliminar o potencial comunicativo (emancipatório) inscrito no segundo diagnóstico habermasiano. Isso ocorre porque esses diagnósticos não brotaram de teorizações abstratas a partir de séries de dados ("teoria tradicional"), mas sim da identificação de forças e relações produtivas na totalidade da práxis social (filiação, reivindicada por Habermas, dos seus dois diagnósticos à "teoria crítica"). A consequência disso está na constatação de que, alteradas as forças e relações que produzem essa práxis social, mudam também as potencialidades ou aporias identificadas pelos diagnósticos teóricos.

Dessa maneira, os potenciais inscritos na reconstrução que Habermas mobiliza em textos como "Facticidade e validade" e "Soberania popular como processo" dependem fundamentalmente da existência concreta de esferas públicas não apenas como "modelos normativos", mas como redes concretas de formação discursiva da vontade coletiva, reguladas pela conjunção entre autonomia pública e privada. Isso já pressupõe, em sua base, a eficiência de arranjos jurídicos que estruturem essas redes, e a efetiva existência de cidadãos autônomos tanto em sentido privado quanto em sentido público. Os potenciais do diagnóstico dependem, também, de que o direito democraticamente legitimado seja capaz de concretamente constituir a autoridade administrativa, o que significa assumir que todas as decisões confiadas ao poder administrativo tenham que necessariamente estar vinculadas a esse lastro comunicativo calcado na democracia, o que não se confunde com a representação política em sua dimensão formal, nem com a supressão da racionalidade discursiva por mecanismos plebiscitários. Dependem, por fim, de que o direito público reúna condições de eficácia institucional para de fato vincular a 
racionalidade instrumental que orienta o exercício e a disputa na política, racionalidade calcada na autolegitimação do poder pelo poder.

Essas dimensões de dependência entre diagnóstico e facticidade colocam o problema do deficit empírico do direito público em contextos como o brasileiro. Tal deficit se revela particularmente grave no que toca às seguintes aporias: (i) dificuldades na formação de uma rede de instituições administrativas efetivamente procedimentalizadas, capazes de constituir espaços de racionalidade discursiva nas atividades burocráticas; (ii) resistências quanto à democratização substantiva da administração pública, por meio de expedientes autolegitimadores como "prerrogativas de função", "mérito administrativo", "juízos de conveniência e oportunidade não controláveis pelo público"; (iii) limitações relacionadas ao ônus argumentativo e às dificuldades de legitimação democrática das escolhas "técnicas" e "discricionárias; (iv) esgarçamento da legalidade administrativa no contexto de indeterminação dominado pela principiologização do direito e pela crescente sobreposição entre o poder administrativo e o poder judiciário; (v) subintegração de agentes e grupos sociais na esfera pública; e (vi) exclusão ou incidência seletiva de direitos subjetivos em relação a agentes de diferentes classes e grupos sociais.

Longe de resolver todas essas questões, a continuidade entre os dois diagnósticos aqui analisados revela o caráter crítico da abordagem habermasiana, corroborando o potencial desse referencial como mapa eficiente de questões a serem enfrentadas pelo direito público em contextos concretos, e como horizonte de identificação de gargalos e pontos de dificuldade a serem tematizados e corrigidos no curso de mudanças jurídico-institucionais.

A perspectiva de Habermas sobre o direito público, como definida no Capítulo IV de "Facticidade e validade", serve, portanto, como guia das potencialidades e aporias contidas em arranjos institucionais e em sua reprodução em dinâmicas sociais concretas. No caso do direito ocupado com o poder administrativo, tais dificuldades, como se ilustrou há pouco, remontam à facticidade democrática do exercício do poder, à capacidade constitutiva do direito público na regulação do domínio administrativo instrumental, e à efetiva vinculação do exercício do poder ao direito comunicativamente articulado. Apesar das dificuldades, os respectivos potenciais emancipatórios sugerem, desde a emergência da modernidade política, que vale a pena enfrentar as aporias. Essa é precisamente a tarefa do direito público encarado em sua potência constitucional.

São Paulo, abril de 2019. 


\section{Referências}

FINLAYSON, James Gordon. Habermas: a very short introduction. Nova York: Oxford University Press, 2012.

GIDDENS, Anthony. Sobre trabalho e interação em Habermas. In: GIDDENS, Anthony. Política, sociologia e teoria social: encontros com o pensamento social clássico e contemporâneo. Tradução: Cibele Saliba Rizek. São Paulo: Unesp, 2011.

HABERMAS, Jürgen. A crise do Estado de bem-estar social e o esgotamento das energias utópicas. In: HABERMAS, Jürgen. A nova obscuridade. Tradução Luiz Repa. São Paulo: Unesp, 2015.

HABERMAS, Jürgen. Acerca da legitimação com base nos direitos humanos. In: HABERMAS, Jürgen. A constelação pós-nacional: ensaios políticos. Tradução de Márcio Seligmann-Silva. São Paulo: Littera Mundi, 2001.

HABERMAS, Jürgen. Between facts and norms: contributions to a discourse theory of law and democracy. Translated by William Rehg. Cambridge: MIT Press, 1996a.

HABERMAS, Jürgen. Popular sovereignty as procedure. In: HABERMAS, Jürgen. Between facts and norms: contributions to a discourse theory of law and democracy. Translated by William Rehg. Cambridge: MIT Press, 1996b.

HABERMAS, Jürgen. Teoria do agir comunicativo. Tradução Paulo Astor Soethe. São Paulo: Martins Fontes, 2012. v. 2.

HABERMAS, Jürgen. The structural transformation of the public sphere: an inquiry into a category of bourgeois society. Cambridge: MIT Press, 1991.

HART, Herbert Lionel Adolphus. The concept of law. Oxford: Clarendon Press, 1994.

HONNETH, Axel. Teoria crítica. In: GIDDENS, Anthony; TURNER, Jonathan (org.). Teoria social hoje. Tradução de Gilson César. São Paulo: Unesp, 1999.

HORKHEIMER, Max. Teoria tradicional e teoria crítica. In: CIVITA, Victor (ed.). Benjamin, Habermas, Horkheimer, Adorno. São Paulo: Abril Cultural, 1975. (Coleção Os Pensadores, v. 48).

MACCORMICK, Neil. H. L. A. Hart. São Paulo: Campus-Elsevier, 2009. (Coleção Teoria e Filosofia do Direito).

MELO, Rúrion Soares. Marx e Habermas: teoria crítica e os sentidos da emancipação. São Paulo: Saraiva, 2013.

NOBRE, Marcos; REPA, Luiz (org.). Habermas e a reconstrução: sobre a categoria central da teoria crítica habermasiana. Campinas; São Paulo: Papirus, 2012.

TROPER, Michel. A filosofia do direito. São Paulo: Martins Fontes, 2008. 
